\title{
Splenic Manifestation of Chronic Myelogenous Leukemia, BCR-ABL1 Positive
}

National Cancer Institute

\section{Source}

National Cancer Institute. Splenic Manifestation of Chronic Myelogenous Leukemia, BCR-

ABL1 Positive. NCI Thesaurus. Code C7303.

Infiltration and expansion of the red pulp and sinusoids of the spleen by chronic

myelogenous leukemia, BCR-ABL1 positive. 